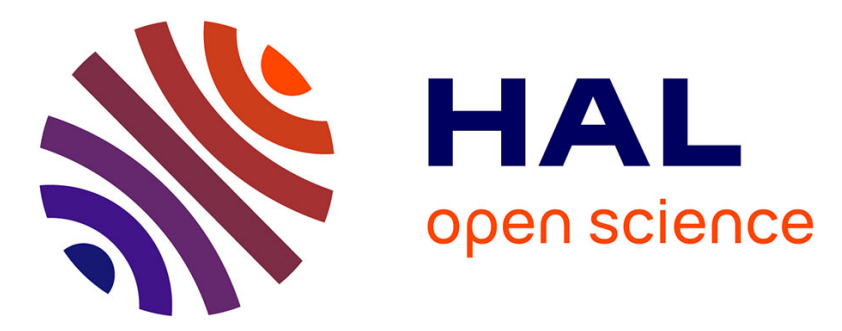

\title{
Prediction the AC Breakdown Voltage in Point/Plane Air Gaps with Barrier Using Design of Experiments
}

\author{
Abdelghani Rouini, Djillali Mahi, Tahar Seghier
}

\section{To cite this version:}

Abdelghani Rouini, Djillali Mahi, Tahar Seghier. Prediction the AC Breakdown Voltage in Point/Plane Air Gaps with Barrier Using Design of Experiments. TELKOMNIKA Indonesian Journal of Electrical Engineering, 2014, 12 (12), pp.8033 - 8041. 10.11591/telkomnika.v12i12.6771 . hal01575134

\section{HAL Id: hal-01575134 \\ https://hal.science/hal-01575134}

Submitted on 18 Aug 2017

HAL is a multi-disciplinary open access archive for the deposit and dissemination of scientific research documents, whether they are published or not. The documents may come from teaching and research institutions in France or abroad, or from public or private research centers.
L'archive ouverte pluridisciplinaire HAL, est destinée au dépôt et à la diffusion de documents scientifiques de niveau recherche, publiés ou non, émanant des établissements d'enseignement et de recherche français ou étrangers, des laboratoires publics ou privés. 


\title{
Prediction the AC Breakdown Voltage in Point/Plane Air Gaps with Barrier Using Design of Experiments
}

\author{
Abdelghani Rouini ${ }^{1}$, Djillali Mahi ${ }^{2}$, Tahar Seghier ${ }^{2}$ \\ Department of Electrical Engineering, Faculty of Science and Technology, \\ University Amar Telidji of Laghouat, BP 37G, Laghouat 03000, Algeria \\ *Corresponding author, e-mail: a.rouini@univ-djelfa.dz'1, d.mahi@mail.lagh-univ.dz², \\ t.seghier@mail.lagh-univ.dz ${ }^{3}$
}

\begin{abstract}
Breakdown voltage characteristics of air gaps considered a random process we have investigated how to find relevant statistical different leading to breakdown or with standing during an impulse voltage test under the same condition for a plane high voltage electrode and a grounded electrode configuration.In the present paper methods of the modelling and prediction of the AC breakdown voltage in point-plane air gaps are investigated. An analysis based on experiments design method has been developed with indicates that. Measurements to contain some relevant information test at early stages in reduced time frame investigation were done on a point-plane with barrier varying in position and size. The barrier used was mounted vertically between the electrodes. The use of methodology of experiments design is one of this methods and present an original idea in high voltage prediction problems several factors were considered,namely the distance between electrodes and different parameters of the barrier such us is dimension and his holes. The experimental results are compared with results from numerical simulations. We firstly present the principals of this model then we apply it to the study of barrier effect.A good agreement has been found between the computed and experimental results
\end{abstract}

Keywords: experiments design method, breakdown voltage, barrier, point-plane gap, factors

Copyright @ 2014 Institute of Advanced Engineering and Science. All rights reserved.

\section{Introduction}

The knowledge of the condition of ionisation and propagation of electrical discharge is of great interest to well understand the mécanismes leading to breakdown [1]. The barriers are widely used in many high voltage devices.It is well known that the dielectric strength of long air gap is significantly increased by the insertion of an insulating barrier. The insulating structure to different stress and particularly to the discharge phenomena [2, 3].

The effectiveness of the barrier depends on the geometry (the dimension and the position of the barrier, and the physical nature on the barrier [4,5]. The investigation have been done experimentally and simulated in order to study the breakdown phenomena of solid dielectric barrier. The presence a hole within the barrier significantly reduces the dielectric strength of the system. Tests are conducted to measure the $50 \mathrm{~Hz} \mathrm{AC}$ breakdown voltage of small air gap [6-8]. The results of the test series show how the breakdown voltage varies with the distance between the electrodes, the size and the material of barrier, the relative position of the electrodes and the barrier between them [9].

As a result, the breakdown voltage varies due to the size of the barriers and the maximum flashover voltages are observed when the barriers are positioned at the nearest point to the electrode and the small sized barriers become effective only in very small air gaps [1016]. An analysis based on experimental design method has been developed which indicates that measurements do contain some relevant information test at early stages in reduced time frame.

The principle of this methodology is to carry out a schedule of experiments designed to obtain the most accurate information for a specific problem with a minimum number of experiments $[17,18]$. Its advantages were proved in different areas of application, especially in chemistry and mechanics, where a large number of parameters have to be optimized simultaneously. This method has been used in electronics, circuits and devices,components and packaging, for the design optimization in some industrial electronics applications and for 
powerful non linear control of power converters [19]. A design space, orregion of interest, must be defined, that is, a range of variability must be set for each variable.The number of the variables values can assume in design method is restricted and generally is small [20]. The design method technique and the number of levels are to be selected according to the number of experiments which can be afforded [21, 22].

In this paper work, in order to modelling the AC breakdown voltage in point-plane gaps arrangement in presence of barrier, the experiments design method is used. The carried out experimental results are taken to build a model which takes into consideration different parameters such as(the relative position of the barrier, its hole and the width of the barrier) that affect the breakdown phenomena.

\section{Material and Methods}

\subsection{Material}

The experimental set-up consists of a high-voltage test transformer $100 \mathrm{kV} / 5 \mathrm{kVA} / 50 \mathrm{~Hz}$, a capacitive voltage divider. Figure 1 and Figure 2 (the experiences have been performed in the laboratory of high voltage University of Biskra )shows the arrangement of electrodes and insulating barrier it contains a point-plan electrode arrangement mounted vertical. The HV electrodes consist a steel needle point on copper of conical in shape $30^{\circ}$. The grounded plan electrode is a circular steel plate of $30 \mathrm{~cm}$ long, $2.8 \mathrm{~cm}$ diameter.

The bakelitte barriers $\left(\varepsilon_{\mathrm{r}}=5.82\right)$ are squares of different widths $(15 \mathrm{~cm}, 20 \mathrm{~cm}$ and 25 $\mathrm{cm})$. and different holes $(5 \mathrm{~mm}, 10 \mathrm{~mm}$ and $15 \mathrm{~mm}$ ) and its thicknesses is $1 \mathrm{~mm}$, an aluminum plan grounded. To change the positions for several barriers, carriers bakelite are used.

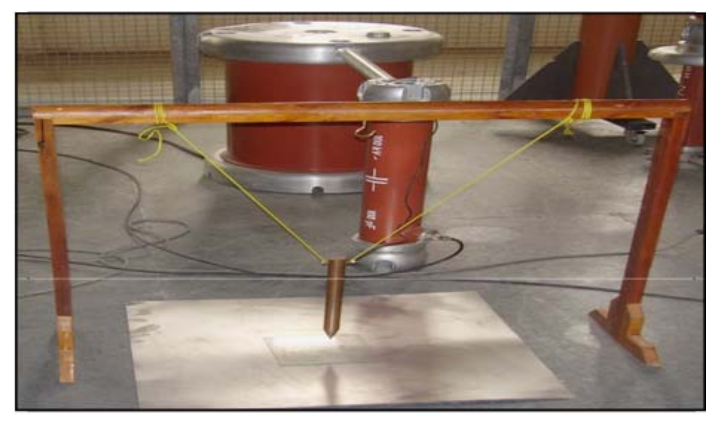

Figure 1. View of real test cell

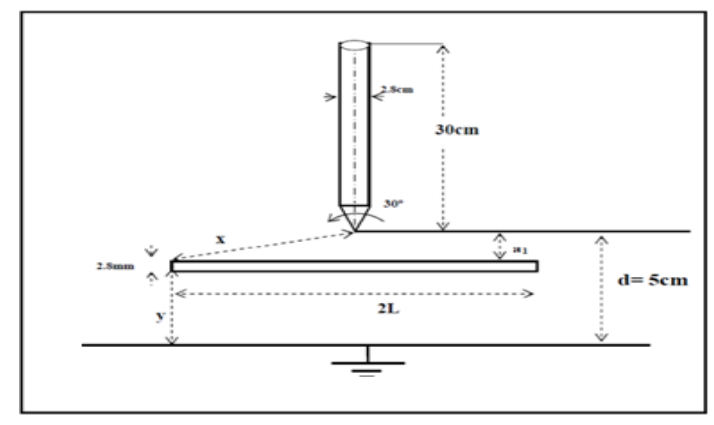

Figure 2. Scheme of the test cell

The barrier is mounted vertically between the electrodes Its surfaces are checked after each breakdown.

\subsection{Methods}

The principle of the technical design of experiments consists in varying levels of one or more factors simultaneous (which are variable, discrete or continuous) in each test. This will help to reduce significantly the number of experiments to be performed.While increasing the number of studied factors, detecting interactions between the factors and optimal compared to are sponse, that is to say aquantity used as standard and allowing to easily modeling results.

The traditional methodology for an experimental design consists of four (4) steps: first the preparation study including the definition of responses characterizing the objectives, which is the main scope of this paper and the determination of factor levels, then the choice of factors and experimental domain in the second step, the proposed model it self and finally, the mathematical model.

\subsubsection{Definition of Responses Characterizing the Objectives}

We want to measure the influence of the following factors Where:R $(\mathrm{cm})$ is the relative position of the barrier, $\mathrm{H}(\mathrm{mm})$ is the hole in the barrier and $\mathrm{W}(\mathrm{cm})$ is the width of the barrier. 


\subsubsection{Choice of Factors and Expérimental Domain}

Determining the field of study is closely related to the initial knowledge held on the physical phenomenon under study, but also to the objectives of the experiment. In addition,care must be taken to minimize the cost of the study, expressed as number of tests.

We recall now that the results of the study will be valid only on the range of variation of the factors considered. The main factors considered in this plan experiments are:

Table 1. Levels of factors studied

\begin{tabular}{lrrr}
\hline Factors & $\mathrm{R}(\mathrm{cm})$ & $\mathrm{H}(\mathrm{mm})$ & $\mathrm{W}(\mathrm{cm})$ \\
\hline Level -1 & 2 & 5 & 15 \\
Level 0 & 3 & 10 & 20 \\
Level +1 & 4 & 15 & 25 \\
\hline
\end{tabular}

\subsubsection{A Proposed Model}

Our choice fell on composite face-centered plans for the study of response surfaces. A face-centered composite design is defined by: two start points by parameter and positioned on each of the axes. These points contribute to the evaluation. The quadratic terms of the polynomial model, i.e., they give information about the curvature of the surface of response: The total number of tests to be conducted, $\mathrm{N}$ depends on the number of factors $\mathrm{k}$ studied and the number of répétitions in the center of the domain, $\mathrm{n}_{0}$.

$$
\begin{aligned}
& \mathrm{N}=2^{\mathrm{K}}+2 . \mathrm{K}+\mathrm{n}_{0} \\
& \mathrm{n}_{0}=3 \quad \text { With } \quad \mathrm{N}=2^{3}+2.3+3=17
\end{aligned}
$$

Table 2. Composite plan for the study centered on three Factors

\begin{tabular}{ccccr}
\hline Experiments & \multicolumn{4}{c}{ Factor } \\
No & $\mathrm{R}(\mathrm{cm})$ & $\mathrm{H}(\mathrm{mm})$ & $\mathrm{W}(\mathrm{cm})$ & \\
\hline 1 & -1 & -1 & -1 & 65,84575 \\
2 & -1 & 1 & -1 & 62,73575 \\
3 & -1 & -1 & 1 & 62,204331 \\
4 & -1 & 1 & 1 & 55,459331 \\
5 & 1 & -1 & -1 & 66,70175 \\
6 & 1 & 1 & -1 & 67,38675 \\
7 & 1 & -1 & 1 & 67,525331 \\
8 & 1 & 1 & 1 & 64,575331 \\
9 & 0 & -1 & 0 & 66,602838 \\
10 & 0 & 1 & 0 & 63,572838 \\
11 & 0 & 0 & 1 & 65,797838 \\
12 & 0 & 0 & 1 & 65,797838 \\
13 & -1 & 0 & 0 & 64,114838 \\
14 & 1 & 0 & 0 & 69,100838 \\
15 & 0 & 0 & 0 & 67,526216 \\
16 & 0 & 0 & 0 & 67,506216 \\
17 & 0 & 0 & 0 & 67,486216 \\
\hline
\end{tabular}

The last three rows of Table 2 corresponds to a test center considered expérimental field, which should be repeated $\mathrm{n}_{0}$ times to ensure certain properties the matrix experiments.

So that it meets the requirement of uniform precision, ensuring a nearly constant variance within the experimental range.

Whether the vector of model coefficients analytical sought:It is defined by The coefficients vector of the analytical model is defined as follow:

$$
\mathrm{b}=\left(\mathrm{X}^{\mathrm{t}} \cdot \mathrm{X}\right)^{-1} \mathrm{X}^{\mathrm{t}} \cdot \mathrm{y}
$$

Where $\mathrm{X}$ are the matrix experiment, $\mathrm{X}^{\mathrm{t}}$ are the transpose matrix experiment, $\mathrm{y}$ the breakdown voltage (the response). The number of unknown parameters $\left(b_{i}\right)$ of the polynomial is determined from the following formula: 
$\mathrm{b}=\frac{(\mathrm{K}+2) !}{\mathrm{k} ! 2 !} \Rightarrow \mathrm{b}=\frac{(3+2) !}{3 ! 2 !}=10$

Finally, the model is given by equation:

$$
\begin{aligned}
& y=b_{0}+\sum_{i=1}^{3} b_{i} \cdot x_{i}+\sum_{i=1}^{3} b_{i i} \cdot X_{i}^{2} \sum_{i=1}^{2}\left[\sum_{j=i+1}^{3} b_{i j} \cdot X_{I} \cdot X_{J}\right] \\
& y=b_{0}+b_{1} x_{1}+b \cdot x_{2}+b_{3} \cdot x_{3}+b_{11} \cdot x_{1}{ }^{2}+b_{22} \cdot x_{2}{ }^{2}+b_{33} \cdot x_{3}{ }^{2}+b_{12} \cdot x_{12} \\
& +b_{13} \cdot x_{13}+b_{23} \cdot x_{23}
\end{aligned}
$$

\subsubsection{Mathematical Models}

Estimation of model coefficients,we have used Matlab program,which gives an analytical form of the response studied surface and they are calculated by using Equation (3) (Table 3).

Table 3. Coefficients of mathematical model

\begin{tabular}{cc}
\hline Response & $\begin{array}{c}\text { Breakdown voltage } \mathrm{U}_{\mathrm{c}}(\mathrm{kV}) \\
\text { Experimental design domain }\end{array}$ \\
\hline Constant & 67,5262162 \\
R & 2,493 \\
H & $-1,515$ \\
W & $-1,61320946$ \\
R.H & 0,94875 \\
R.W & 1,11625 \\
H.W & $-0,90875$ \\
R $^{2}$ & $-0,91837838$ \\
H $^{2}$ & $-2,43837838$ \\
W $^{2}$ & $-0,11516892$ \\
\hline
\end{tabular}

So we can write the mathematical model (experimental domain) as follows:

$$
\begin{aligned}
& U_{C}=67,5262162+2,49 . R-1,515 . H-1,61320946 . W+0,94875 . R . H+ \\
& 1,11625 . R . W-0,90875 . H . W-0,91837838 . R^{2}-2,43837838 . H^{2} \\
& -0,11516892 . W^{2}
\end{aligned}
$$

The obtained results can be plotted to compare the measured responses with the estimated one. For this, it is necessary to plot the adequacy of the model. Measured responses are placed on the abscissa and estimated responses are on the ordinate (Figure 3 ). The cloud points is aligned with the line $y=x$, which means that accuracy of the model is pretty good.

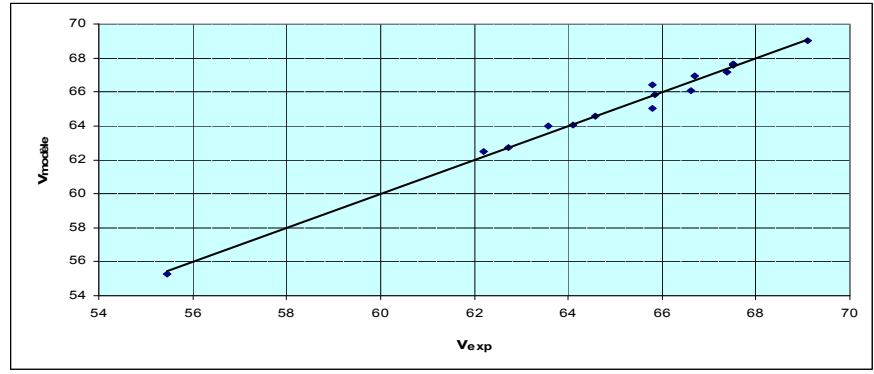

Figure 3. Graph model adequacy

The descriptive quality of the model is illustrated here but a second analysis of variance will possible to verify this conclusion. 


\subsubsection{Statistical Analysis of the Model}

The equation of the empirical model is only a approximation of reality. Estimating coefficients of of the second degree polynomial model is based on test results that are, each treatment plan experience, the particular values of a random variable. The implementation of statistical tests must allowto pass judgment on the results obtained in namely a model describing the variation of the response in the experimental field. This step Statistical analysis of the results in the construction of table of regression analysis and determining the descriptive quality of the model. Regression analysis is to explain the total change in the response from the defined sum of squared deviations between the results test and their average.

Statistical analysis of the model as a whole isfollowed by the construction of a statistical test which consists in affirming that the model does not allow describe the a equal to $5 \%$.

The regression analysis table is used to achieve immediately calculate the coefficient determination $R^{2}, R_{\text {ajus }}^{2}$ and $Q^{2}$ : descriptive quality of the model will be evaluated, these take values following:

Table 4. Coefficients of determination of the descriptive quality of the model

\begin{tabular}{ccc}
\hline $\mathrm{R}^{2}$ & $\mathrm{R}_{\text {ajus }}^{2}$ & $\mathrm{Q}^{2}$ \\
\hline 0,989384 & 0,994678 & 0,975735 \\
\hline
\end{tabular}

A good descriptive quality is assured because the Coefficients $R^{2}, R_{\text {ajus }}^{2}$ and $\mathrm{Q}^{2}>0.9$ (near the unity), which reflects the good quality of the model.For a risk of $\alpha=5 \%$, $\mathrm{N}-\mathrm{P}=17-10=7$ From the Student table:

$$
t_{\text {crit }}=(0,05,7)=2.37
$$

The effect will be significant at the risk of $5 \%$ if $\left(t_{i}>2.37\right)$. In addition, $t_{i}$ is calculated by using Equation (8) and (9)

$$
t_{i}=\frac{\left|b_{i}\right|}{s_{i}}
$$

Table 5. Test of significance of the coefficients

\begin{tabular}{crcc}
\hline Factors & Effet & $\mathrm{t}_{\mathrm{i}}=2.37$ & results \\
\hline Constante & 67,5262162 & 560,47 & significatif \\
$\mathrm{R}$ & 2,493 & 20,69 & significatif \\
$\mathrm{H}$ & $-1,515$ & 12,57 & significatif \\
$\mathrm{W}$ & $-1,61320946$ & 13,39 & significatif \\
R.H & 0,94875 & 7,87 & significatif \\
R.W & 1,11625 & 9,26 & significatif \\
H.W & $-0,90875$ & 7,54 & significatif \\
$\mathrm{R}^{2}$ & $-0,91837838$ & 7,62 & significatif \\
$\mathrm{H}^{2}$ & $-2,43837838$ & 20,24 & significatif \\
$\mathrm{W}^{2}$ & $-0,11516892$ & 0,96 & non significatif \\
\hline
\end{tabular}

From Table 5, only the coefficients providing descriptive quality of model will be preserved. That is to reject the coefficients $\left(\mathrm{W}^{2}\right)$ The reduced model equation becomes:

$\mathrm{U}_{\mathrm{C}}=67,5262162+2,49 . \mathrm{R}-1,515 . \mathrm{H}-1,61320946 . \mathrm{W}+0,94875 . \mathrm{R} \cdot \mathrm{H}$

$+1,11625$. R. W - 0,90875. H. W - 0,91837838. $\mathrm{R}^{2}-2,43837838$. $\mathrm{H}^{2}$

In this case the confidence interval of an effect is given by:

$\left[b_{i}-1,96.0,189\right]$ lower limit, $\left[b_{i}+1,96.0,189\right]$ Higher limit. 


\section{Results and Analysis}

The validation of the results given by the model is to check whether the assumptions made in departure of experiments are well verified.

Validation can be carried performing test complementary outside the testing plan experiments to validate the model behavior obtained by the experimental design.

In our case study, we took the made test to study the influence of parameters Apart from testing the experimental design. the results of these tests are compared with results of the mathematical model .

\subsection{Influence of the Relative Position Barrier on the Breakdown Voltage}

Figure 4 shows the experimental and predicted breakdown voltage as a function of the relative position of the barrier values of the barrier for different width $(15 \mathrm{~cm}, 20 \mathrm{~cm}$ and $25 \mathrm{~cm})$ of the barrier. The hole in the barrier is $(5 \mathrm{~mm})$.Different distances between the point and the barrier $(0$ to $5 \mathrm{~cm})$ were studied.

The breakdown voltage of the gap-point barrier plan significantly improved when the point touches the barrier, then it decreases. As the we close barrier plan,the optimum on the breakdown voltage corresponds to the case where the barrier is contacted with the point.

The prediction values are situated between the two boundaries of the area of risk of $5 \%$. This means that the founded model by the experimental design method is perfect.
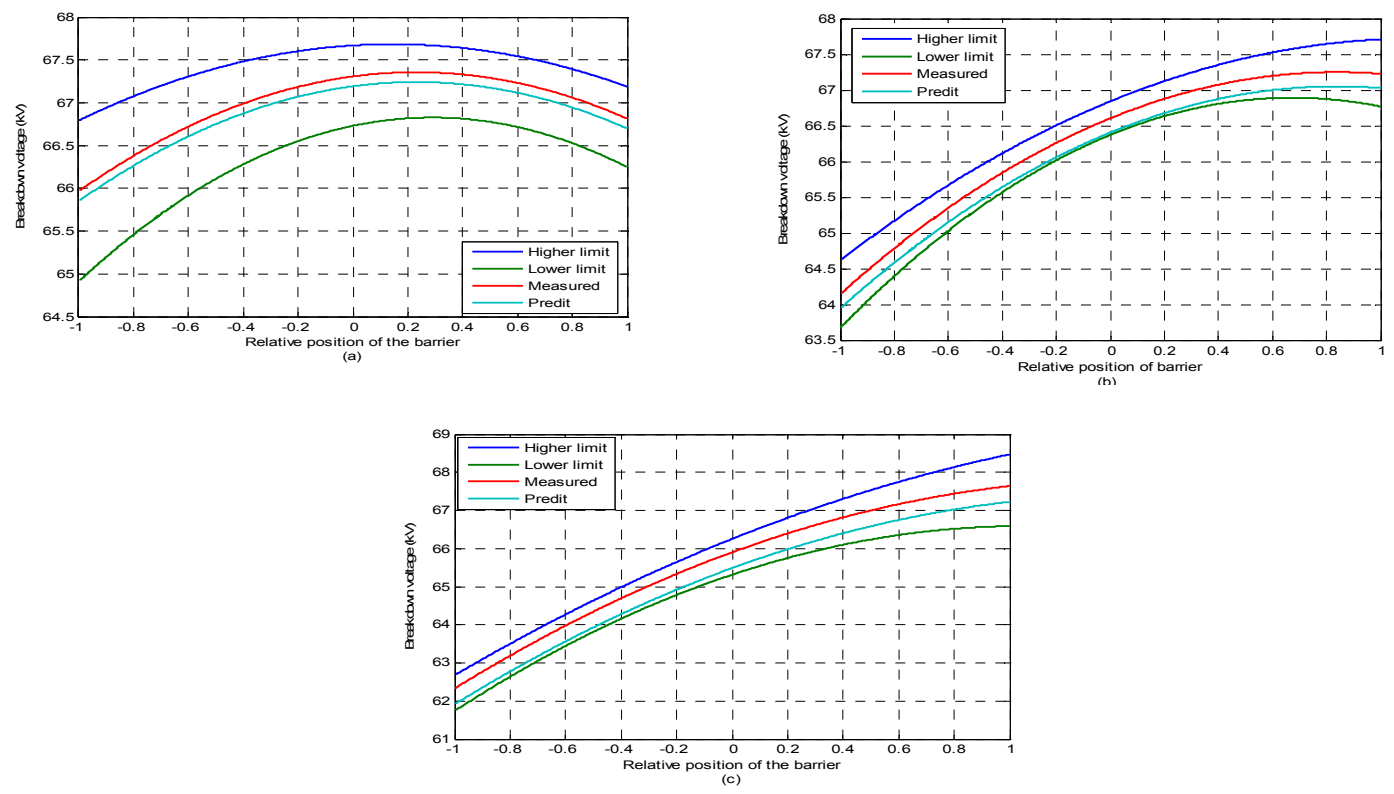

Figure 4. Influence of the relative position of barrier on the breakdown voltage: different width (a) $15 \mathrm{~cm},(\mathrm{~b}) 20 \mathrm{~cm}$ and (c) $25 \mathrm{~cm}$, the hole $(5 \mathrm{~mm})$

\subsection{Influence of the Hole in the Barrier on the Breakdown Voltage}

In this test, holes in the middle of the barrier varies $(5 \mathrm{~mm}, 10 \mathrm{~mm}$ and $15 \mathrm{~mm})$. The relative position of the barrier values for $4 \mathrm{~cm}$, different width $(15 \mathrm{~cm}, 20 \mathrm{~cm}$ and $25 \mathrm{~cm})$.

We see from Ffigure 5 as perforation of the barrier affects considerably well insulated the indeed, when the barrier is in contact with the point, with centered hole diameter $(5 \mathrm{~mm})$. In this case the discharge does not pass through the hole but takes the path edge of the barrier plan.

Thus discharge does not tend to go through the small diameter hole, probably because of the concentration load the middle of the barrier, and then see deflected of zone hole.This explains the barrier contribution of the gap to improve the rigidity dielectric system.

This can be interpreted by the fact that increasing the diameter of the hole.The prediction values are situated between the two boundaries of the area of risk of $5 \%$. 

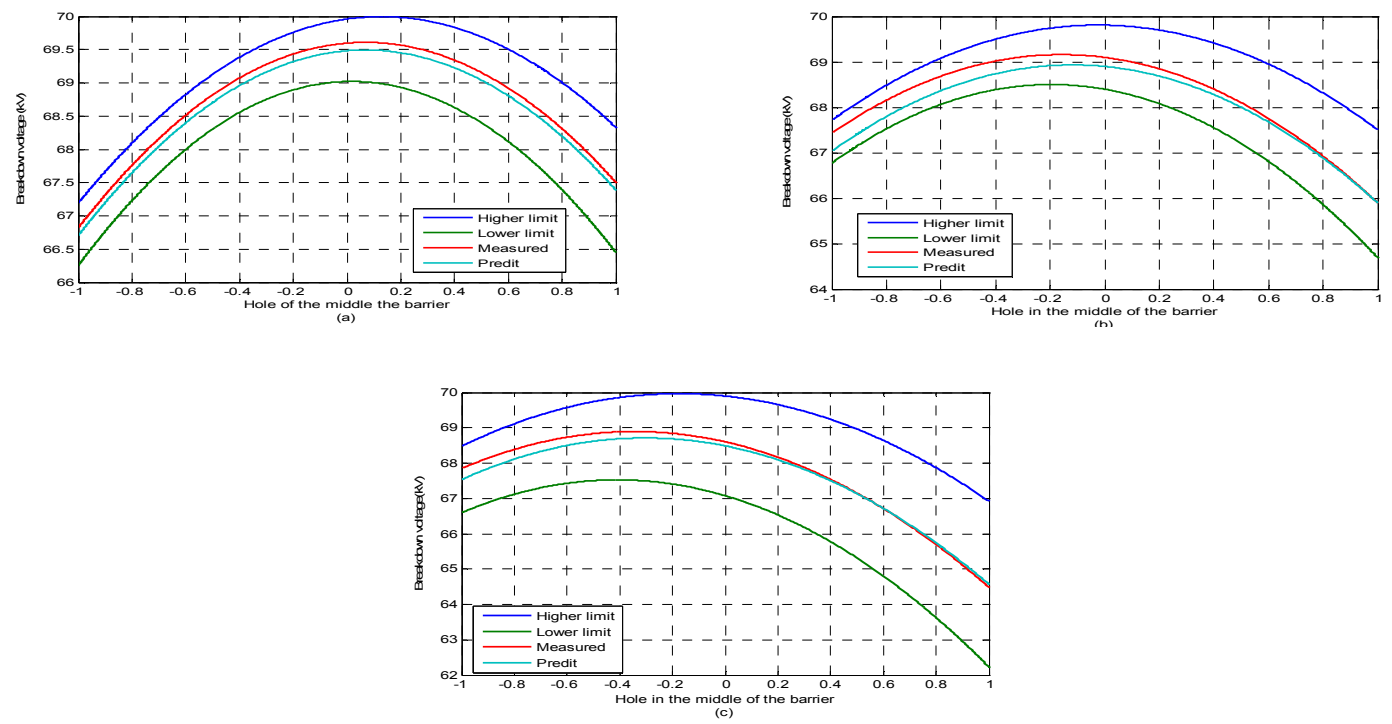

Figure 5. Influence of the hole in the middle of the barrier on the breakdown voltage: different width (a) $15 \mathrm{~cm},(\mathrm{~b}) 20 \mathrm{~cm}$ and (c) $25 \mathrm{~cm}$ )

\subsection{Influence of the Width of the Barrier on the Breakdown Voltage}

In this test shouts, the different distances between electrodes and barrier $(2 \mathrm{~cm}, 3 \mathrm{~cm}$ and $4 \mathrm{~cm})$, the hole in the middle of the barrier for $(5 \mathrm{~mm})$, different width of the barrier $(15 \mathrm{~cm}$, $20 \mathrm{~cm}$ and $25 \mathrm{~cm}$ ).

we see clearly, the breakdown voltage is very low with the increasing of large widths of the barrier and very big with the decreasing of them. This can be explained by the fact that the screen plays a geometric opstacle.

From Figure 6, the breakdown voltage decreases with increasing of the barrier widths. The prediction values are situated between the two boundaries of the area of risk of $5 \%$. This means that the model founded by the experimental design method is perfect.
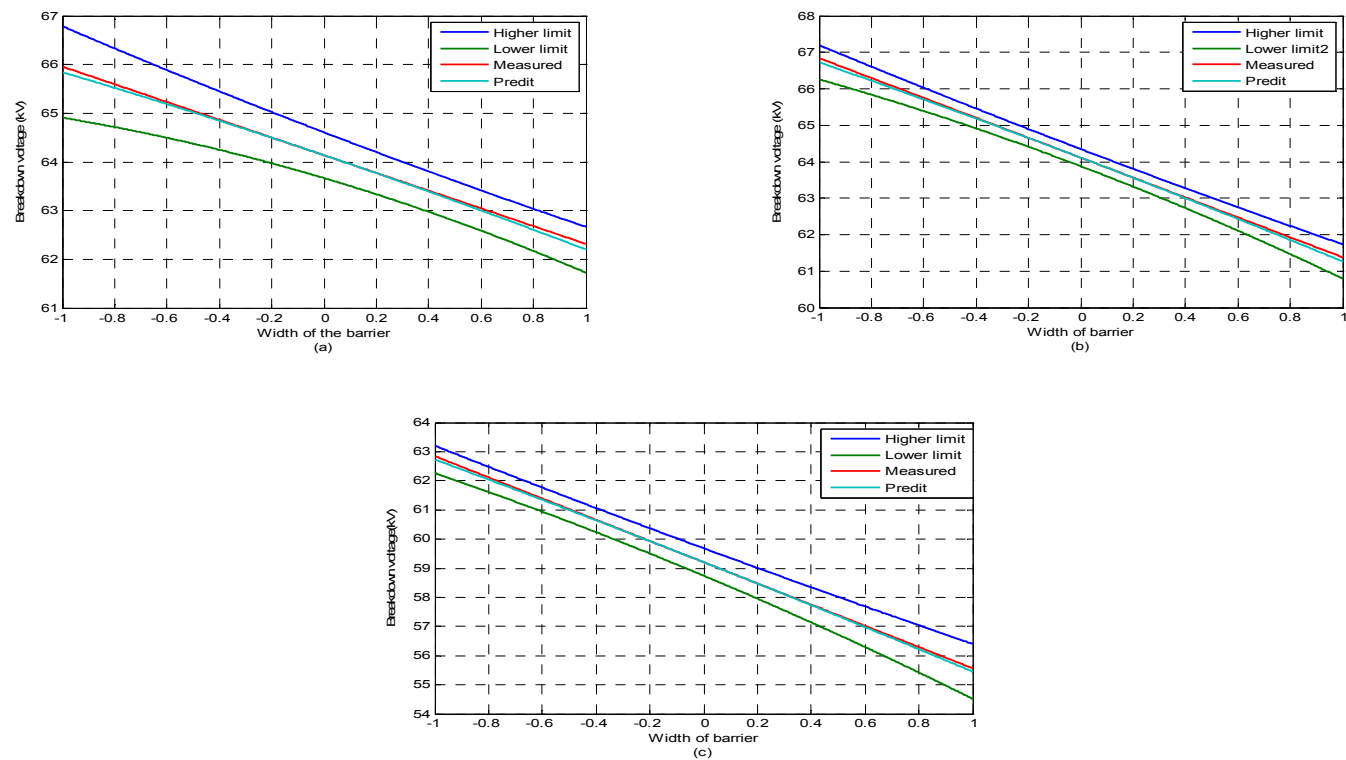

Figure 6. Influence of the width of the barrier on the breakdown voltage: different relative position of the barrier 
Considering experimental conditions in which we have worked and approximations we have made in the numerical model, we can say that results are satisfactory and we note that the experimental results are well within the range of $5 \%$ confidence error.

In experiments design method, verification experiments should be done to determine optimum conditions and compared with experimental values. In this study, all values are within confidence levels, as a result of the verification experiments.

\section{Conclusion}

Investigational results shown that the experiments design method is a useful tool to search parameters influencing the objective fixed and optimization. Methodology of experiments was giving guidance on the effects of different factors. It consists in a first step to make search parameters influencing the objective fixed. For this, the use of the method response surface turns outto be highly effective, because it allowsto classify the effect of parameters in the order of importance. The study on the effects of factors has on the one hand and restricting choose the parameters of the desired model on the other hand to define the limits of the universe speech.

A model with a good description of the studied system thus have been defined, and led to improvement of system performance. The modelling of the dielectric breakdown in point-plan arrangement with insulating barrier in air interval has been investigated. We have proposed a mathematical modelling by using experiments design method. It leads to analyze the interactions between different parameters: distance between electrodes, diameter of the barrier and the relative position. This methodology has provided good results and helps to minimize the cost of study, expressed in number of tests.It has been shown, that the use of this methodology is very useful for tracking the influent operating parameters on insulation reliability and for the lifetime modelling. In this study we can say that the methodology of experiement design show a good performance to investigations in the analysis of different discharge steps of the air interval.

\section{References}

[1] Holtzhausen JP, Volsov WL. HighVoltage Engineering Practice and Theory. Stellenbosch. 2014.

[2] Haddad A, Warn D. Advanced in HighVoltage Engineering. The institution of engineering and technology, London, 2007.

[3] Bourek Y, Mokhnache L, Nait Said N, Kattan R. Determination of Ionization Conditions Characterizing the Breakdown Threshold of a Point Plane Air Interval Using Fuzzy Logic. Electric Power Systems Research. 2011; 81: 2038-2047.

[4] Adamiak K, Attan P. Simulation of Discharge Corona in Pointe Plane Configuration. Journal on Electrostaic. 2004; 61: 85-98.

[5] Ducasse O, Papageorghiou L, Eichwald O, Spyron N, Yousfo M. Critical Analysis on two Dimentional Point-to Plane Streamer Simulation Using Finit Element Method and Finit Volume Method. IEEE Trans Plasm. 2007; 35(5):1287-1300.

[6] Gallimiberti I, Bachiegga G, Boudiou A. Lalanche P. Fondamentale Processus in Long air Gap Discharge, Compte rendu physique. 2002; 3(1): 1135-1359.

[7] Chen GU, Liang ZW, Bin FJ, et al. Influence of Rod Electrode Structure on Suitching Impulse Discharge Characteristics of Rod Plane air Gap. Proceeding oh the CSSE. 2011: 120-127.

[8] Kojma H, Hotia K, Twata T, Hayakara N, Yanjita N, et al. L'influence of Gap Lenth on Discharge Channel Propagation and Breakdown Mécanisme in Air. Proceeding $17^{\text {th }}$ ISH, 2011, D37

[9] Arvello L, et al. A New Static Calculation of the Streamer Region for Long Spark gaps. Journal on electrostatic. 2012; 70:15-19.

[10] Ottia K, Kgma H, Hayakawo N, et al. Impulse Breakdown Mechanism Based on Discharge Propagation Process Under non Uniform Electric Field in Air. CEIDP. 2011; 5. B-9

[11] Rouini A, Mahi D. Investigation on the Insulating Barriers Influence in the Air Gap Pointe-Plane by Field Estimatation in Presence Space Charge using Finite Volume, XII Annuel Seminario on Automation Industriel and Instrumentation, Tangier. Maroc. 2014.

[12] Dascalescu L, Mihalciou A. Norme internationale.Insulating liquids Determination of the breakdown voltage of a industrial frequency test method, Second Edition, CEI 156, 1995 (in French).

[13] Boubakeur A, Mokhnache L, Feliachi A. Theoretical Investigation on the Barrier Effect on Pointe-Plane air gap Breakdown Voltage Based on Streamer Criterion. IEE Proc SCI Meas, Technol. 2004; 151(3): 167-174.

TELKOMNIKA Vol. 12, No. 12, December 2014 : 8033 - 8041 
[14] Topalis FV, Danikas M G. Breakdown in air gaps with Solid Insulating Barrier Under Impulse Voltage Stress. Facta Unversitas, SA, Electrical Engineering. 2005; 18: 87-104.

[15] MA Abd Allah, Sayed A Ward, Amr A Youssef. Effect of Functionally Graded Material of Disc Spacer with Presence of Multi-Contaminating Particles on Electric Field inside Gas I-nsulated Bus Duct. International Journal of Electrical and Computer Engineering (IJECE). 2013; 3(6): 831-848.

[16] MA Abd Allah, Sayed A Ward, Amr A Youssef. Effect of Coating of Earthed Enclosure and Multi Contaminating Particles on Breakdown Voltage inside Gas Insulated Bus Duct. International Journal of Electrical and Computer Engineering (IJECE). 2014; 4(4): 471-485.

[17] Atkinson AC, Donev AN. Optimum Experimental Designs, Oxford University Press, New York, 1992.

[18] Montgomery DC. Design and Analysis of Experiments, John Wiley\& Sons, Inc. 2005.

[19] J Faucher, P Maussion: On-line Electrical Quality Improvement of a Single-Phase Boost Rectifier with Fuzzy Controller and Experimental Designs, Electromotion. 2006; 13(3): 221-232.

[20] Andu I, Nafiu LA, Ilimiese PK. Matrix Approach to the Experimental Design, of Response Surface Methodology, Journal of science Education and technology. 2009; 2(1).

[21] Bisgoard S. Must Process be in stastical control befor conducting design Experiments, Quality Engineering. 2008; ASQ20(2): 143-176.

[22] Timont gomery Douglas. Design and Analysis of Experiments. $8^{\text {th }}$ ed, Hodoken, $\mathrm{Nj}$, John Wily \&Sons. 2013. 